Document downloaded from:

http://hdl.handle.net/10251/115876

This paper must be cited as:

Valencia-Sullca, CE.; Vargas, M.; Atarés Huerta, LM.; Chiralt, A. (2018). Thermoplastic cassava starch-chitosan bilayer films containing essential oils. Food Hydrocolloids. 75:107115. doi:10.1016/j.foodhyd.2017.09.008

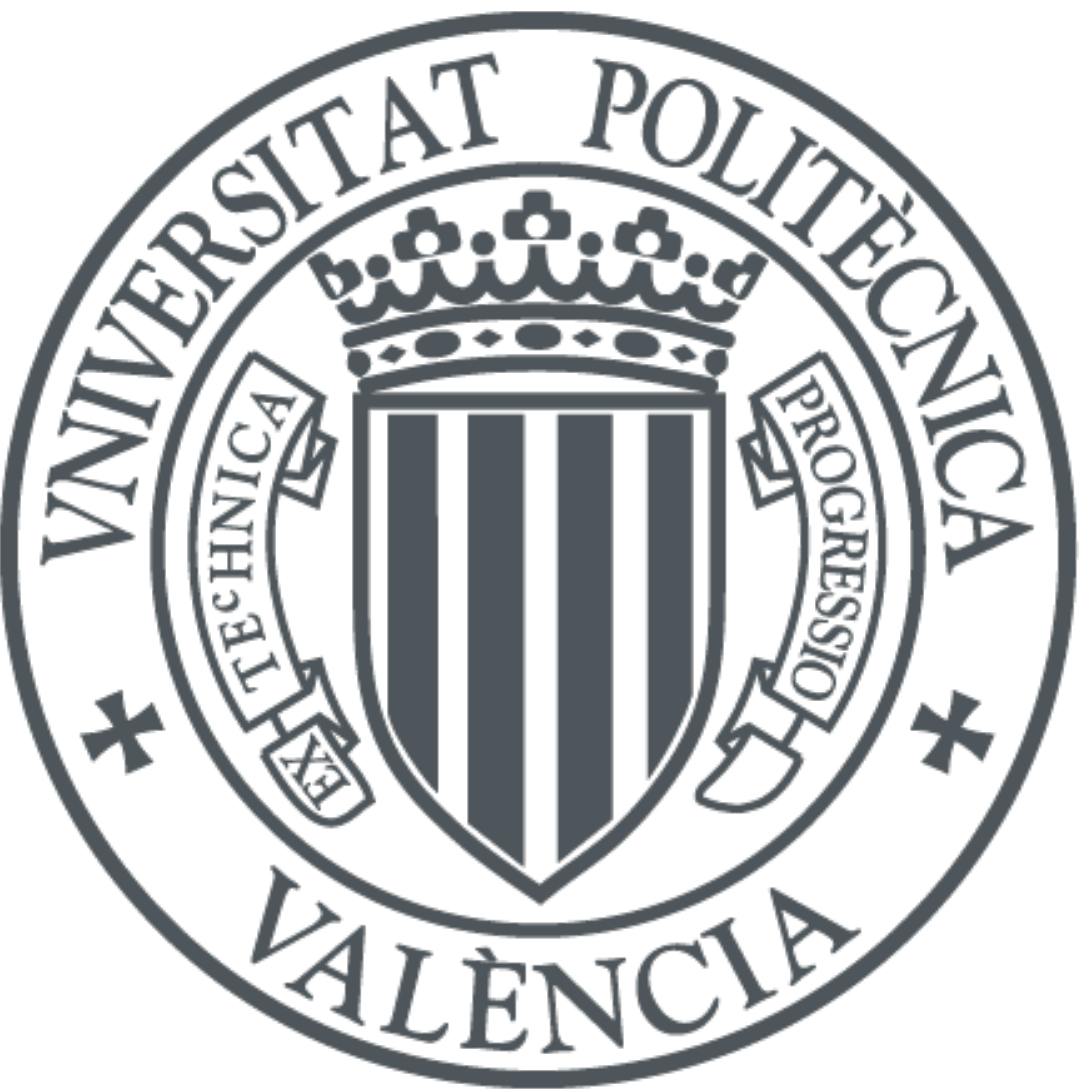

The final publication is available at

http://doi.org/10.1016/j.foodhyd.2017.09.008

Copyright Elsevier

Additional Information 


\section{Thermoplastic cassava starch-chitosan bilayer films containing essential oils} Cristina Valencia-Sullca, María Vargas*, Lorena Atarés, Amparo Chiralt Instituto de Ingeniería de Alimentos para el Desarrollo, Universitat Politècnica de València

\section{*mavarco@tal.upv.es}

\section{Abstract}

Starch-chitosan bilayer films, containing or not essential oils in the casted chitosan layer were obtained by thermo-compression. Bilayer films exhibited a good interfacial adhesion and better mechanical resistance than starch monolayers, although they were less stretchable and less transparent. Starch-chitosan films were effective at controlling the bacterial growth in pork meat, but the thermal treatment applied to obtain the bilayers reduced their antimicrobial properties as compared to chitosan monolayers. The addition of essential oils did not promote any antimicrobial action in chitosan mono and bilayer films applied to pork meat. The final amount of essential oils in the films was very limited probably due to the losses occurred during film processing method. Other strategies to incorporate the essential oils into chitosan-based films should be used to improve their final retention in the film matrix and their effective release into the coated food.

Keywords: polysaccharide, thermal degradation, tensile properties, antimicrobial.

\section{Introduction}

In recent years, the interest in biodegradable films has grown mainly due to general concern about the disposal of conventional synthetic plastic materials since their full degradation generally requires a long period of time (Xu, Kimb, Hanna, \& Nag, 2005).

Starch has been considered for many years as a biodegradable polymer with a high potential for packaging applications (Doane, Swanson, \& Fanta, 1992; Shogren, 1998). 
Biodegradable films based on hydrocolloids such as starch can act as barriers to control the transfer of moisture, oxygen, carbon dioxide, lipids, and flavor components, thus preventing quality deterioration and increasing the shelf-life of food products (Ghanbarzadeh \& Oromiehi, 2009; Naushad Emmambux \& Stading, 2007). The use of starch from different sources (corn, cassava, wheat, rice, potato, pea, etc.) to obtain biodegradable plastics is being extensively studied since starch is abundant and accessible at a relatively low cost (Mali, Grossmann, García, Martino, \& Zaritzky, 2006; Khan, Bilal Khan Niazi, Samin, \& Jahan, 2017), Thermoplastic Starch: A Possible Biodegradable Food Packaging Material—A Review. Journal of Food Process Engineering, 40: n/a, e12447. doi:10.1111/jpe.12447). Several authors have shown the possibility to transform native starch into thermoplastic-like products under restructuring and plasticization conditions (Swanson, Shogren, Fanta, \& Imam, 1993). Furthermore, the feasibility of processing starch by using plastic-processing equipment has long been demonstrated (Tomka, 1991).

Thermoplastic starch (TPS) can be processed in the same way as synthetic plastics through extrusion and injection units (Avérous, Moro, Dole, \& Fringan, 2000) and thermocompression (Flores, Costa, Yamashita, Gerschenson, \& Grossmann Eiras, 2010; Pellissari, Grossmann, Yamashita, \& Pineda, 2012; Thunwall, Boldizar, \& Rigdahl, 2006). The thermocompression method is useful as a processing method because of its simplicity and capability of producing films (López et al. 2014). During the extrusion of starch, the combination of shear, temperature and plasticizers allows for producing a molten thermoplastic material by disruption of the native crystalline granular structure and plasticization. This plasticized starch could be suitable for injection molding or thermoforming (Avérous, Fringan \& Moro, 2001). TPS is a very hydrophilic product (Avérous et al., 2000) and yields films with high water sensitivity (Zobel, 1988) and poor mechanical properties (Van Soest, 1996), which change with time (crystallization due to ageing and plasticization by water adsorption). The combination of starch with chitosan $(\mathrm{CH})$ led to the improvement of the functional 
properties of the films while conferring them antimicrobial properties (Bonilla, Vargas, Atarés, \& Chiralt, 2014).

Chitosan is a biodegradable biopolymer that has shown excellent properties such as bio-compatibility, non-toxicity and adsorption to negatively charged interfaces since it is positively charged in acid media (Dutta, Dutta, \& Tripathi, 2004; Lertsutthiwong, Ng, Chandrkrachang, \& Stevens, 2002; Rizzi, \& Pinto, 2007; Weska, Moura, Batista, Youn, No, \& Prinyawiwatkul, 2007).

The use of films as carriers of antimicrobial agents, such as essential oils, represents an interesting approach for the external incorporation of such active ingredients onto food system surfaces. Essential oils, which exhibit both antimicrobial and antioxidant capacity (Bakkali, Averbeck, Averbeck, \& Idaomar, 2008), were incorporated into the formulation of antimicrobial films based on chitosan to extend the shelf-life of minced pork meat (Bonilla et al., 2014). Oregano essential oil (OEO) has been shown to possess higher antimicrobial activity than other essential oils such as thyme or basil essential oil (Burt, 2004), and it has been effective at inhibiting the microbial growth of some foodborne microorganisms, such as Staphylococcus aureus, Escherichia coli and Bacillus subtilis (Lv, Liang, Yuan, \& Li, 2011). Carvacrol, the main compound of OEO, was effective in inhibiting the growth and survival of Listeria monocytogenes, Aeromonas hydrophila, and Pseudomonas fluorescens (de Sousa et al. 2012). Cinnamon leaf essential oil (CLEO) is recognized for its aroma and medicinal properties (Ayala-Zavala et al., 2008; Singh, Srivastava, Singh, \& Srivastava, 2007). The main component of CLEO is eugenol (70-95\%), followed by cinnamaldehyde, which can be present in a proportion of $1-5 \%$ (Vangalapati, Satya, Prakash, \& Avanigadda, 2012). In addition, CLEO antimicrobial and antifungal properties have also drawn great attention in many studies (Chang, Chen, \& Chang, 2001; Kim, Park, \& Park, 2004; Park, Lee, Lee, Park, \& Ahn, 2000; Singh et al., 1995). Essential oils and their active ingredients can diffuse from the film into the coated food to control target microorganisms. In this sense, the combination of biodegradable polymers (Starch- 
$\mathrm{CH}$ ) as bilayers, where $\mathrm{CH}$ encapsulates the antimicrobial agent and is not submitted to the heat blending step, can be an interesting approach to obtain new biodegradable films with antimicrobial activity. However, there are not previous studies on the development of these type of bilayer films, to the best of our knowledge.

The aim of this work was to characterize the thermal behavior, optical, barrier, mechanical and antimicrobial properties of bilayer films prepared with thermoplastic starch and chitosan, containing or not oregano or cinnamon leaf essential oil in the chitosan layer.

\section{Materials and methods}

\subsection{Materials}

Cassava starch was supplied by Quimidroga S.A. (Barcelona, Spain), high molecular weight chitosan (practical grade, $>75 \%$ deacetylation degree, Batch MKBP1333V), polyethylene glycol (PEG), Tween 85 and Glycerol (Gly) were supplied by SigmaAldrich (Madrid, Spain). Oregano (OEO) and cinnamon leaf (CLEO) essential oils were provided by Herbes del Molí (Alicante, Spain) and $\mathrm{Mg}\left(\mathrm{NO}_{3}\right)_{2}$ was obtained from Panreac Química, S.A. (Castellar del Vallés, Barcelona, Spain). Pork meat, which was used for the microbiological study, was purchased in a local supermarket. Tryptone Phosphate Water (peptone buffered water), Violet Red Bile Agar (VRB agar) and Plate Count Agar (PCA) were provided by Scharlau Microbiology (Barcelona, Spain).

\subsection{Film preparation}

Chitosan-based films were obtained by casting as previously described by Bonilla et al. (2014). Chitosan $(1.0 \% \mathrm{w} / \mathrm{w})$ was dispersed in an aqueous solution of glacial acetic acid $(1.0 \% \mathrm{v} / \mathrm{w})$ under magnetic stirring at $40{ }^{\circ} \mathrm{C}$ for $24 \mathrm{~h}$. The film-forming dispersions (FFDs) were obtained by adding OEO or CLEO at $0.25 \%(w / w)$ and Tween 85 at 0.1 $\%(w / w)$. FFDs were homogenized with a rotor-stator (13500 rpm, 4 min, Yellow Line 
113 DL 25 Basic, IKA, Janke y Kunkel, Germany) and degassed at room temperature with

114 a vacuum pump. Subsequently, FFDs were cast in a framed and leveled polytetrafluorethylene (PTFE) plate (diameter $=15 \mathrm{~cm}, 5.6 \mathrm{mg}$ solids $/ \mathrm{cm}^{2}$ ) and dried at room temperature at $45 \%$ relative humidity $\mathrm{RH}$. Sample codes for chitosan films, with or without OEO and CLEO were: $\mathrm{CH}, \mathrm{CH}: \mathrm{OEO}$ and $\mathrm{CH}$ :CLEO. Cassava starch films (CS) were obtained by melt blending and compression molding. Thermoplastic CS pellets were obtained by melt blending in a roll-mill (Model LRM-M100, Labtech Engineering, Thailand) at $160^{\circ} \mathrm{C}$ for $30 \mathrm{~min}$ with the plasticizer blend (glycerol:PEG) at $30 \%$ with respect to the starch, and $24 \%$ of water, which evaporates during the process. Polymer: plasticizer mass ratio was 1:0.3 and Gly: PEG mass ratio was 3:0.05. The pellets were conditioned at $53 \% \mathrm{RH}$ and they were submitted to compression molding with a hot plates hydraulic press (Model LP20, Labtech Engineering, Thailand) at $160^{\circ} \mathrm{C}$ and $1.2 \times 10^{7} \mathrm{~Pa}$. This film was named as CS. Chitosan-starch bilayer films were obtained by compressing CS film and chitosan based films, at $100{ }^{\circ} \mathrm{C}$ for 2 min by means of the hot-plates hydraulic press. The obtained bilayer films were named as follows: $\mathrm{CS}-\mathrm{CH}$; $\mathrm{CS}-\mathrm{CH}$ :OEO and CS-CH:CLEO. Taking into account the relative weight of each layer with the same area, the ratio S:CH was $3: 1$.

All films were stored at $25^{\circ} \mathrm{C}$ and $53 \% \mathrm{RH}$ for one week prior performing the analysis of thermal, barrier, optical and mechanical properties. Film thickness was measured using a Palmer digital micrometer (Comecta, Barcelona, Spain) to the nearest 0.001 $\mathrm{mm}$. Six to eight random positions in each film sample were considered.

\subsection{Field emission scanning electron microscopy}

The microstructural analysis of the cross-sections of the bilayer films was carried out by means of a field emission scanning electron microscope (Ultra 55, Zeiss, Cambridge, UK). The film samples were maintained in desiccators with $\mathrm{P}_{2} \mathrm{O}_{5}$ to guarantee that water was not present in the sample and two samples per film formulation were 
analyzed. Film pieces, $0.5 \mathrm{~cm}^{2}$ approximately in size, were cryofractured from films and fixed on copper stubs, gold coated, and observed using an accelerating voltage of 2 $\mathrm{kV}$.

\subsection{Thermogravimetric analysis}

A thermogravimetric analyzer (TGA/SDTA 851e, Mettler Toledo, Schwerzenbach, Switzerland), equipped with an ultra-micro weighing scale $( \pm 0.1 \mu \mathrm{g})$, was used to determine the thermal stability of the film samples under nitrogen flow $(50 \mathrm{~mL} / \mathrm{min})$. The analysis was carried out using the following temperature program: heating from 25 to $600{ }^{\circ} \mathrm{C}$ at a $10^{\circ} \mathrm{C} / \mathrm{min}$ heating rate. Approximately $3 \mathrm{mg}$ of each sample were used in each test, considering at least two replicates for each one. Initial degradation temperature $\left(T_{0}\right)$ and the temperature of the maximum degradation rate $\left(T_{\max }\right)$, were registered from the first derivative of the resulting weight loss curves.

\subsection{Mechanical properties}

Mechanical properties were measured with a Universal Test Machine (TA.XT plus, Stable Micro Systems, Haslemere, England), following the ASTM standard method D882 (ASTM, 2001). Equilibrated film samples (25 mm wide and $100 \mathrm{~mm}$ long) were mounted in the film-extension grips (A/TG model), which were set $50 \mathrm{~mm}$ apart. Tension test was performed at $50 \mathrm{~mm} / \mathrm{min}$. Stress-strain curves were obtained and the tensile strength at break (TS), percentage of elongation at break $(\varepsilon)$ and elastic modulus (EM) were calculated. Ten replicates carried out per formulation.

\subsection{Water vapor and oxygen permeability}

The water vapor permeability (WVP) of the films was determined by using the ASTM E96-95 (ASTM, 1995) gravimetric method, considering the modification proposed by McHugh et al. (1993). Films were selected for WVP tests based on the lack of physical defects such as cracks, bubbles, or pinholes. Distilled water was placed in Payne 
permeability cups (3.5 cm diameter, Elcometer SPRL, Hermelle /s Argenteau, Belgium) to expose the film to $100 \% \mathrm{RH}$ on one side. Once the films were secured, each cup was placed in a relative humidity equilibrated cabinet at $25^{\circ} \mathrm{C}$, with a fan placed on the top of the cup to reduce resistance to water vapor transport. $\mathrm{RH}$ of the cabinets $(53 \%)$ was held constant using oversaturated solutions of magnesium nitrate-6-hydrate (Panreac Química, SA, Castellar del Vallés, Barcelona). The cups were weighed every $1.5 \mathrm{~h}$ for $24 \mathrm{~h}$ by using an analytical scale (ME36S Sartorius, Germany, $0.0001 \mathrm{~g}$ ). To calculate the water vapor transmission rate, the slopes of the steady state period of the curves of weight loss as a function of time were determined by linear regression. From this data, water vapor permeability values were obtained, considering the average value of film thickness in each case. The equation proposed by McHugh et al. (1993) was used to correct the effect of concentration gradients established in the stagnant air gap inside the cup.

The oxygen barrier capacity of the films was evaluated by measuring oxygen permeability (OP) by means of an Ox-Tran 1/50 system (Mocon, Minneapolis, USA) at $25^{\circ} \mathrm{C}$ (ASTM Standard Method D3985-95, 2002). Measurements were taken at 53\% $\mathrm{RH}$ in films previously equilibrated at the same $\mathrm{RH}$. Films were exposed to pure nitrogen flow on one side and pure oxygen flow on the other side. The OP was calculated by dividing the oxygen transmission rate by the difference in the oxygen partial pressure on the two sides of the film, and multiplying by the average film thickness. At least three replicates per formulation were taken into account.

\subsection{Optical properties}

The transparency of the films was determined by applying the Kubelka-Munk theory (Hutchings, 1999) for multiple scattering to the reflection spectra. When the light passes through the film, it is partially absorbed and scattered, which is quantified by the absorption $(\mathrm{K})$ and the scattering $(\mathrm{S})$ coefficients. Internal transmittance $\left(\mathrm{T}_{\mathrm{i}}\right)$ of the films was quantified using Equation (1). In this Equation $R_{0}$ is the reflectance of the film on 
an ideal black background. Equation (2) and (3) are used to calculate $a$ and $b$ parameters, respectively. $R$ in equation 2 is the reflectance of the sample layer backed by a known reflectance $\left(R_{g}\right)$. The surface reflectance spectra of the films were determined from 400 to $700 \mathrm{~nm}$ with a spectrocolorimeter CM-5 (Konica Minolta Co., Tokyo, Japan) on both a white and a black background. All measurements were performed at least in triplicate for each sample on the free film surface during its drying. In bilayer films, measurements were carried out on the $\mathrm{CH}$ layer.

207

Color coordinates of the films, $\mathrm{L}^{*}, \mathrm{C}^{*}{ }_{\mathrm{ab}}\left(\right.$ Equation (4)) and $\mathrm{h}^{*}{ }_{\mathrm{ab}}$ (Equation (5)) from the CIELAB color space were determined, using D65 illuminant and $10^{\circ}$ observer, and taking into account $R_{\infty}$ (Equation 6), which is the reflectance of an infinitely thick layer of the material.

$$
h_{a b}^{*}=\operatorname{arctg}\left(\frac{b^{*}}{a^{*}}\right)
$$

$$
R_{\infty}=a-b
$$

Whiteness index (WI) was determined according to equation 7.

$$
\mathrm{WI}=100-\left(\left(100-L^{*}\right)^{2}+a^{* 2}+b^{* 2}\right)^{0.5}
$$

Gloss was measured using a flat surface gloss meter (MultiGloss 268, Minolta, Langenhagen, Germany) at an angle of $60^{\circ}$ with respect to the normal to the film surface, according to the ASTM standard D523 (ASTM, 1999). Prior to gloss measurements, films were conditioned at $25^{\circ} \mathrm{C}$ and $53 \% \mathrm{RH}$ for one week. Gloss measurements were carried out over a black matte standard plate and were taken in 
triplicate. Results were expressed as gloss units, relative to a highly polished surface of standard black glass with a value close to 100. For bilayer films, gloss was measured on the $\mathrm{CH}$ layer. For $\mathrm{CH}$ casted monolayer films, gloss measurements were performed on the free film surface for water evaporation.

\subsection{Antimicrobial properties}

230 The antimicrobial capacity of the films (monolayers and bilayers) was tested in pork meat, as described in previous studies (Bonilla et al., 2014). Films were put in contact with the meat surface by the $\mathrm{CH}$ side. Sliced pork meat (about $10 \mathrm{~g}$ ) was placed in petri dishes $(5 \mathrm{~cm}$ in diameter) to obtain the test samples. The surface of the meat slice was coated with the films. Non-coated samples (control) and samples coated with the different types of films were stored in duplicate at $10^{\circ} \mathrm{C}$ for 7 days in a thermostat cabinet (Aqualytic GmbH \& Co, Dortmund, Germany).

To perform microbiological analyses, $10 \mathrm{~g}$ of each sample were aseptically obtained and homogenized in a Stomacher (Bag Mixer 400, Interscience) with $90 \mathrm{~mL}$ of sterile buffered peptone water for $2 \mathrm{~min}$. Aliquots were serially diluted in buffered peptone water and plated out following standard methodologies. Total aerobial and coliform microorganism counts were determined at $0,1,4$ and 7 days. Total aerobial counts were determined in Plate Count agar incubated at $37^{\circ} \mathrm{C}$ for $48 \mathrm{~h}$. Coliform microorganisms were determined in Violet Red Bile Agar incubated at $37^{\circ} \mathrm{C}$ for $48 \mathrm{~h}$. All tests were performed in triplicate.

2.9. Statistical analysis

Statistical analyses were performed through analysis of variance (ANOVA) using Statgraphics Centurion XVI- II. Fisher's least significant difference (LSD) procedure at $95 \%$ was used.

\section{Results and discussion}




\subsection{Microestructure}

253 Figure 1 shows the FESEM micrographs of the cross-section bilayer films, where the two polymer layers can be clearly distinguished. The estimated thickness of each monolayer agreed with the initial values of the respective monolayers, thus maintaining the 3:1 ratio for starch and chitosan layers. The micrographs showed very good adhesion of both polymer layers and no detachment was observed, which confirmed the good compatibility of polymers at the interface. CS:CH bilayers exhibited a continuous homogeneous aspect at both phases, while starch layer showed some micro-cracks, which are related with the more brittle nature of this film under the observation conditions, (theoretical 0 water content), as reported by Jiménez, Fabra, Talens, \& Chiralt (2012) for starch films. Moreover, the absence of starch granules, points to the effectiveness of shear and thermoprocessing at gelatinizing the starch granules. In the CS:CH bilayers with oregano or clove essential oils, the oil droplets or their voids created after cryofracture can be clearly distinguished in the $\mathrm{CH}$ layer.

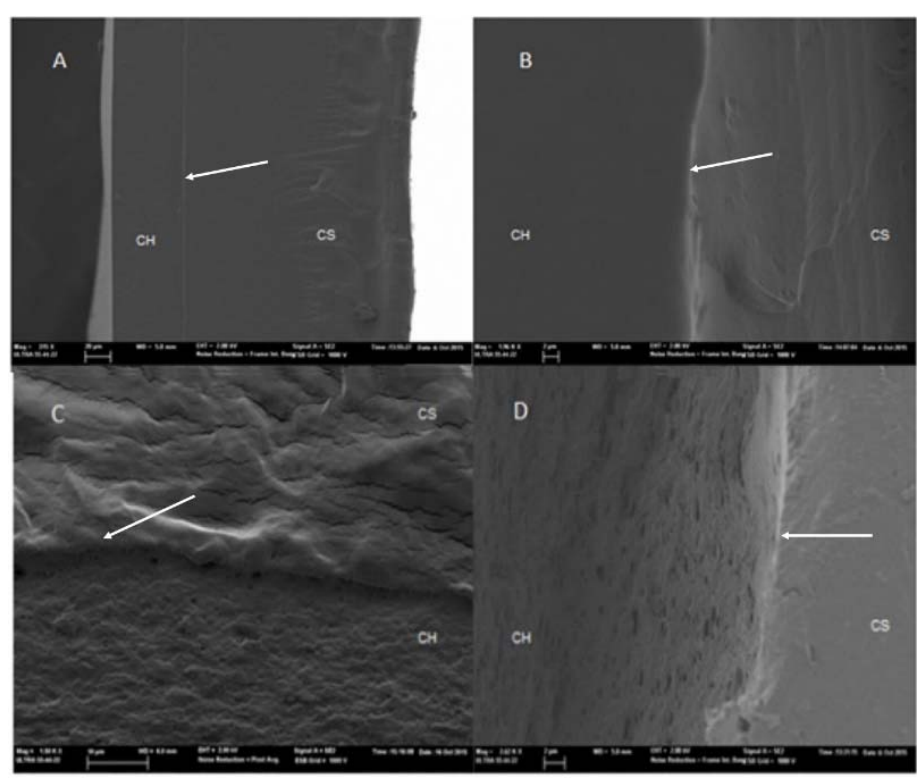

Figure. 1. FESEM micrographs of cross-sections of bilayer films $A$ and $B$ ) $\mathrm{CS}-\mathrm{CH}$ at layer interface. 


\subsection{Thermal characterization}

273 The thermal degradation of the films was analyzed by TGA, which provides information 274 about the thermal stability of polymers and the potential effect of the essential oils added, due to their potential diffusion into both layers and interactions with each macromolecule (Ortega-Toro, Jiménez, Talens, \& Chiralt, 2014). Figure 2 shows the typical curves of the initial mass losses of the monolayers and bilayers, and the derivative curves with the peaks associated with the different weight losses caused by thermal degradation.
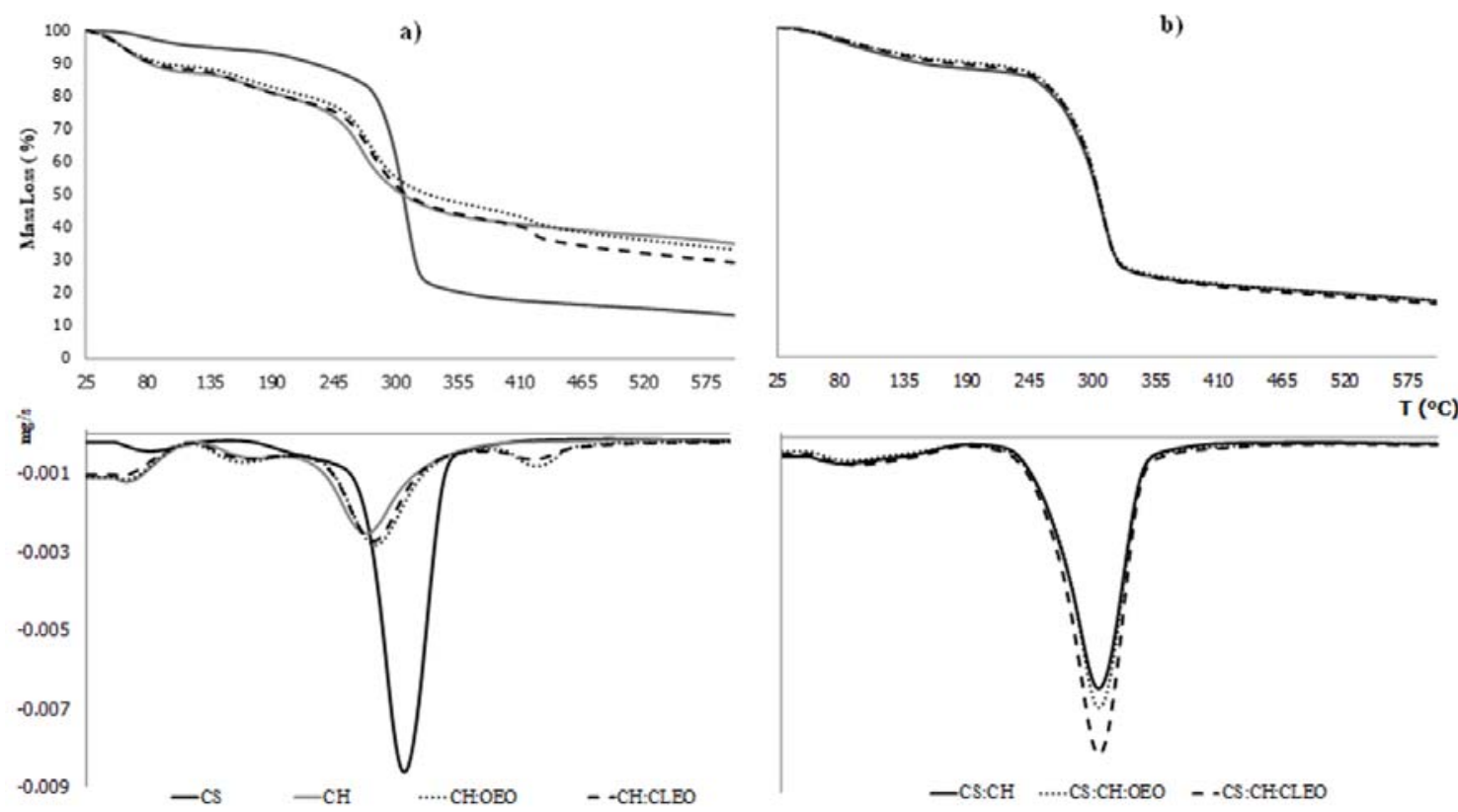

Figure 2. Typical thermogravimetric curves (weight loss vs. temperature) and first derivative ( $\mathrm{mg} / \mathrm{s}$ vs temperature) for a) monolayer films and b) bilayer films.

All films exhibited weight loss below $130^{\circ} \mathrm{C}$, which must be attributed to the loss of adsorbed and bound water. By comparing monolayer samples, $\mathrm{CH}$ films exhibited weight loss between $130-240{ }^{\circ} \mathrm{C}$ (about $10 \%$ ) regardless the presence of $\mathrm{EO}$, which could be due to the partial deamination of the chains at this temperature range (de Brito \& Campana-Filho, 2007). Afterwards, polymer chains degrade in a faster step 
between $270^{\circ} \mathrm{C}$ and $320^{\circ} \mathrm{C}$ showing a less sharp pattern than starch monolayers. $\mathrm{T}_{\max }$ of pure starch films was $308^{\circ} \mathrm{C}$, which is in accordance with previous studies (Dang \& Yoksan, 2015; Pelissari, Grossmann, Yamashita, \& Pineda, 2009). In contrast, $T_{\max }$ of $\mathrm{CH}$ monolayers was $269^{\circ} \mathrm{C}$, near to that reported by other authors (Chen, Wang, Mao, Liao, \& Hsieh, 2008; Lewandowska, 2009; Tripathi, Mehrotra, \& Dutta, 2009; Bonilla, Talón, Atarés, Vargas, \& Chiralt, 2013). As seen in Table 1, no great effect of the EO was observed in the thermodegradation pattern of $\mathrm{CH}$, except for the small loss (about $5 \%)$ that occurred at very high temperature $\left(400-450^{\circ} \mathrm{C}\right)$ and a slight increase in temperature of the maximum degradation rate $\left(T_{\max }\right)$.

298

Table 1. Thermal properties of the films and the essential oils $\left(T_{0}, T_{\max }\right.$, Mass loss 300 during degradation). Mean values and standard deviation, in brackets.

\begin{tabular}{llll}
\hline Sample & $\mathrm{T}_{0}\left({ }^{\circ} \mathbf{C}\right)$ & $\mathrm{T}_{\max }\left({ }^{\circ} \mathrm{C}\right)$ & \%Mass loss \\
\hline CS & $279.44(0.18)^{\mathrm{g}}$ & $308.40(0.14)^{\mathrm{h}}$ & $86.94(0.01)^{\mathrm{g}}$ \\
CH & $241.21(0.05)^{\mathrm{c}}$ & $269.13(0.06)^{\mathrm{c}}$ & $65.15(0.01)^{\mathrm{a}}$ \\
CH:OEO & $248.34(0.42)^{\mathrm{d}}$ & $276.49(0.01)^{\mathrm{e}}$ & $70.79(0.02)^{\mathrm{c}}$ \\
CH:CLEO & $247.4(0.2)^{\mathrm{d}}$ & $275.82(0.01)^{\mathrm{d}}$ & $67.07(0.01)^{\mathrm{b}}$ \\
\hline CS:CH & $271.50(0.17)^{\mathrm{e}}$ & $308.05(0.07)^{\mathrm{g}}$ & $82.92(0.06)^{\mathrm{e}}$ \\
CS: CH:OEO & $274.4(0.4)^{\mathrm{f}}$ & $307.82(0.02)^{\mathrm{f}}$ & $82.81(0.01)^{\mathrm{d}}$ \\
CS:CH:CLEO & $274.6(0.4)^{\mathrm{f}}$ & $307.81(0.03)^{\mathrm{f}}$ & $83.84(0.02)^{\mathrm{f}}$ \\
\hline OEO & $131.2(0.9)^{\mathrm{a}}$ & $151.09(0.12)^{\mathrm{a}}$ & $82.83(0.01)^{\mathrm{d}}$ \\
CLEO & $133.3(0.6)^{\mathrm{b}}$ & $171.75(0.11)^{\mathrm{b}}$ & $82.84(0.01)^{\mathrm{d}}$ \\
\hline
\end{tabular}

The small weight loss in films containing EO could be attributed to the losses of strongly bonded molecules of the essential oils, which are delivered after the polymer degradation. Phenolic compounds, such as the main of components of oregano and clove essential oils, can crosslink with amino groups of the $\mathrm{CH}$ chains, becoming bonded to the matrix (Pelissari et al., 2009; Reyes-Chaparro et al., 2015). This behavior has been also observed by Ramos, Jiménez, Peltzer, \& Garrigós (2012) and Reyes-Chaparro et al. (2015) for essential oils included in $\mathrm{CH}$ matrix. No losses of free essential oils compounds were observed at their volatilization temperature $\left(150^{\circ} \mathrm{C}-170\right.$ ${ }^{\circ} \mathrm{C}$, Table 1), which could indicate that the main part of non-bonded compounds 
evaporated during the film drying step by the steam distillation effect associated to the water evaporation, as observed in previous studies for similar film composition (Perdones, Chiralt, \& Vargas, 2016). Table 1 shows the temperatures for initial and maximum degradation rates of polymers, where the lower values of $\mathrm{CH}$ than those of starch can be observed, as well as the small increase in $\mathrm{T}_{\max }$ of $\mathrm{CH}$ films promoted by essential oils. This effect could be due to the polymer bonding of the EO phenolic compounds, which can slightly modify thermal resistance.

As concerns bilayer films, thermodegradation pattern was very similar and closer to that of starch monolayer, in agreement with the greatest ratio of this polymer in the films. The lack of appreciable differences due to the essential oils, as observed for $\mathrm{CH}$ monolayers, can be related with the small weight fraction of the essential oil in the double sheet. Nevertheless, an additional loss of essential oil compounds could occur during the bilayer thermocompression, mainly due to the steam drag effect associated to the residual water evaporation. Therefore, the processing parameters (temperature and time) should be optimized to avoid excessive evaporation and loss of these compounds incorporated (Dobkowski, 2006; Ramos et al., 2012).

\subsection{Mechanical properties}

As shown in Table 2, CS film exhibited the lowest elastic modulus and tensile strength values and the highest elongation at break. In monolayer films, the addition of EOs to $\mathrm{CH}$ films improved the stretchability and reduced the film stiffness. This effect can be attributed to the developed interactions $\mathrm{CH}$-phenolic compounds that weaken the $\mathrm{CH}$ chain interaction forces, causing interruptions of the polymer chain aggregation in the matrix, which favors the sliding of the chains during film stretching and reduce the strength of the matrix (Bonilla, Atarés, Vargas, \& Chiralt, 2012).

Table 2. Tensile properties (elastic modulus: EM, tensile strength: TS and elongation: $\varepsilon$, at break) of the films. Mean values and standard deviation, in brackets. 


\begin{tabular}{llll}
\hline Film & EM (MPa) & TS (MPa) & $\varepsilon(\%)$ \\
\hline CS & $565(12)^{\mathrm{a}}$ & $17.3(0.4)^{\mathrm{a}}$ & $7.5(0.3)^{\mathrm{f}}$ \\
CH & $1521(52)^{\mathrm{f}}$ & $51(5)^{\mathrm{f}}$ & $4.7(0.3)^{\mathrm{c}}$ \\
CH:OEO & $1078(21)^{\mathrm{d}}$ & $40(3)^{\mathrm{d}}$ & $6.2(0.5)^{\mathrm{e}}$ \\
CH:CLEO & $1417(27)^{\mathrm{e}}$ & $43(3)^{\mathrm{e}}$ & $5.9(0.4)^{\mathrm{d}}$ \\
\hline CS:CH & $921(80)^{\mathrm{c}}$ & $20(2)^{\mathrm{c}}$ & $2.28(0.14)^{\mathrm{b}}$ \\
CS: CH:OEO & $910(38)^{\mathrm{b}}$ & $17(1)^{\mathrm{a}}$ & $1.9(0.2)^{\mathrm{a}}$ \\
CS:CH:CLEO & $918(4)^{\mathrm{d}}$ & $18(2)^{\mathrm{b}}$ & $2(2)^{\mathrm{b}}$ \\
\hline ruperscripts (a-f) within the same column indicate significant differences among formulations $\left({ }^{*} \mathrm{p}<0.05\right)$.
\end{tabular}

342 The obtained values for pure $\mathrm{CH}$ monolayers were similar to those previously reported 343 by Bonilla et al. (2012) and Vargas, Perdones, Chiralt, Cháfer, \& González-Martínez 344 (2011), while the incorporation of OEO and CLEO provoked similar effects to that previously observed by Bonilla et al. (2012) for $\mathrm{CH}$ films containing basil or thyme essential oils. The discontinuities introduced in the chitosan matrix by oil droplets (Figure 1C and 1D), will also contribute to the loss of the film cohesion and mechanical resistance.

All bilayer films showed higher values of EM and TS than CS monolayers, but lower than the $\mathrm{CH}$ monolayer. Likewise, they exhibited lower extensibility than pure CS films and $\mathrm{CH}$-based monolayers, especially when the $\mathrm{CH}$ layer contained essential oils. This behavior demonstrated the reinforcement effect produced by $\mathrm{CH}$ monolayer in the prevalently starch films, despite its lower ratio in the double sheet. However, bilayers lost flexibility probably due to the controlling effect of the $\mathrm{CS}-\mathrm{CH}$ interface at film fracture. The strong $\mathrm{CS}-\mathrm{CH}$ bonding at the interface could make the chain sliding at this zone difficult, provoking film fracture instead of plastic deformation. In this sense, the enhanced film extensibility by EO was not evidenced in thermo-compressed bilayers since the interfacial adhesion of the monolayers controlled the film fracture.

359 Nevertheless, with the $\mathrm{CH}$ layer adhesion, starch films gained stiffness and resistance 360 to fracture. 
Table 3 shows the thickness values of the monolayer and bilayer films. Film thickness of the $\mathrm{CH}$ monolayers slightly decreased when OEO or CLEO was incorporated into the film formulation (from $66 \mu \mathrm{m}$ to $52 \mu \mathrm{m}$ ), which is in accordance with the volatile losses during film formation since a similar total solid amount per surface unit was casted in all cases.

Table 3. Thickness, water vapor permeability (WVP) and oxygen permeability (OP) of the films. Mean values and standard deviation, in brackets.

\begin{tabular}{|c|c|c|c|}
\hline Films & $\begin{array}{l}\text { Thickness } \\
(\mu \mathrm{m})\end{array}$ & $\begin{array}{c}\text { WVP } \\
\left(\mathrm{g} \mathrm{mm} \mathrm{kPa}^{-1} \mathrm{~h}^{-1} \mathrm{~m}^{-2}\right)\end{array}$ & $\begin{array}{c}\text { OP } \\
\left(\mathrm{cm}^{3} \mathrm{~m}^{-1} \mathrm{~s}^{-1} \mathrm{~Pa}^{-1}\right) \times 10^{-13}\end{array}$ \\
\hline CS & $171(5)^{c}$ & $9.38(0.11)^{f}$ & $0.601(0.009)^{b}$ \\
\hline $\mathrm{CH}$ & $66(3)^{b}$ & $5.35(0.14)^{a}$ & $0.781(0.01)^{c}$ \\
\hline CH:OEO & $54(3)^{a}$ & $6.9(0.2)^{d}$ & - \\
\hline CH:CLEO & $552^{a}$ & $5.9(0.3)^{b}$ & - \\
\hline $\begin{array}{l}\text { CS:CH } \\
\text { CS: CH:OEO }\end{array}$ & $\begin{array}{c}221(5)^{\mathrm{e}} \\
209(10)^{\mathrm{d}}\end{array}$ & $\begin{array}{c}7.3(0.6)^{\mathrm{c}} \\
8.03(0.18)^{\mathrm{e}}\end{array}$ & $\begin{array}{c}0.097(0.003)^{\mathrm{a}} \\
-\end{array}$ \\
\hline CS:CH:CLEO & $207(9)^{d}$ & $7.87(0.14)^{e}$ & - \\
\hline
\end{tabular}

A reduction in film thickness due to essential oil addition was previously reported in similar studies, and it was explained by important losses of essential oils during the drying step of the films, mainly due to the steam distillation effect associated to water evaporation (Perdones et al., 2016). Because of this, the thickness of the bilayers that incorporated EO were also slightly lower than that of $\mathrm{CS}: \mathrm{CH}$ bilayer. Nevertheless, no significant flow of the polymer layers occurred during the thermocompression step, as revealed by the final bilayer thickness, which was close to the sum of the respective monolayers. FESEM observations (Figure 1) corroborate that in bilayer films the thickness of each film layer practically maintained its initial value, being the $\mathrm{CS}: \mathrm{CH}$ proportion about $3: 1$. In fact, the low temperature applied in thermocompression (100 ${ }^{\circ} \mathrm{C}$ ) would not justify the polymer flow. However, at this temperature the residual water content of the film layers could evaporate also leading to losses of the EOs by steam distillation effect. 
Table 3 also shows the barrier properties of the films. $\mathrm{CH}$-based monolayer films showed the lowest WVP values, and the addition of essential oils (OEO or CLEO) slightly increased the WVP of CH films. This effect was also observed by Bonilla et al. (2012) and Vargas, Albors, Chiralt, \& González-Martínez (2009), and was attributed to the loss of $\mathrm{CH}$ matrix cohesion associated to the chain interactions with the essential oil compounds. As expected, bilayer films exhibited values of WVP between those found for $\mathrm{CS}$ and $\mathrm{CH}$ monolayers, and essential oils also slightly promoted an increase in the WVP values of bilayer films. As previously reported by Bonilla et al. (2013), the oxygen permeability of pure $\mathrm{CS}$ and $\mathrm{CH}$ films was very low, but the oxygen barrier properties of $\mathrm{CS}: \mathrm{CH}$ bilayers were ever more improved with respect to $\mathrm{CS}$ or $\mathrm{CH}$ monolayers. This effect could be due to the polymer interactions at the interface, which generate a perpendicular layer to mass transfer in the bilayer, with great resistance to the gas transport.

\section{$3.5 \quad$ Optical properties}

401 Figure 3 shows the spectral distribution curves of the internal transmittance $\left(T_{i}\right)$ of the 402 monolayer and bilayer films.

403

404

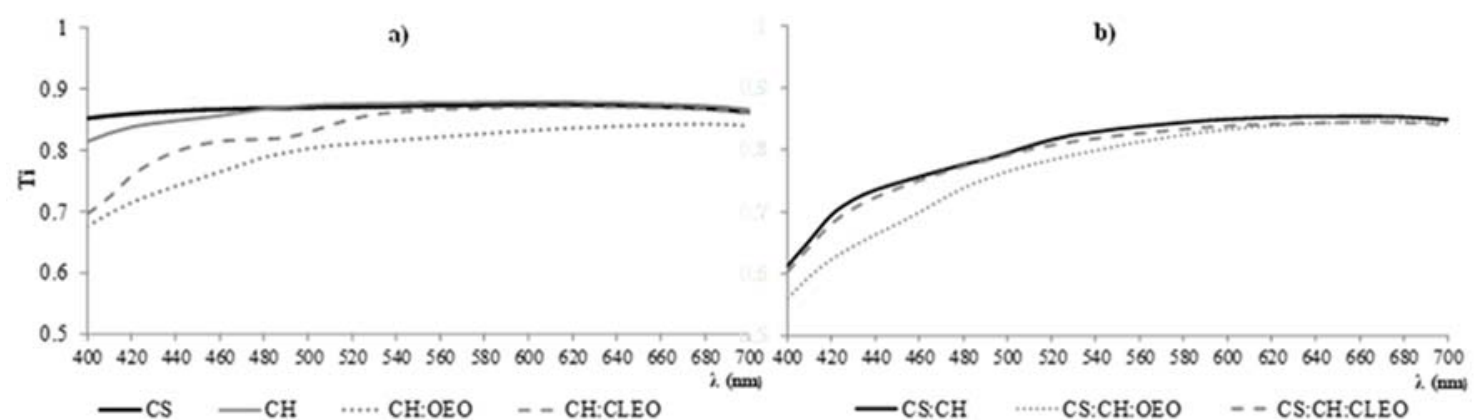

Figure 3. Spectral distribution curves of internal transmittance $\left(T_{i}\right)$ of the $(a)$ monolayer 406 and (b) bilayer films. 
The results obtained revealed significant differences between films. CS monolayer was the most transparent, whereas $\mathrm{CH}$ monolayers showed a higher opacity, especially when they contained essential oils, whose dispersion in the matrix promotes light scattering, thus reducing film transparency to a different extent depending on the essential oil. Oregano EO led to greater reduction in transparency than cinnamon leaf EO, according to the different refractive index and coloration of their constituents, which provoke light selective absorption. As expected, bilayer films were less transparent, since an additional change in the film refractive index occurs at the polymer interface, enhancing light scattering.

From the reflectance spectra of an infinite film thickness, lightness $\left(L^{*}\right)$, hue $\left(h^{*} a b\right)$, chroma (C*ab) and whiteness index (WI) of each film were calculated (Table 4). CS films showed higher lightness and $\mathrm{WI}$ than $\mathrm{CH}$ monolayers. The incorporation of essential oils led to a significant reduction in both $\mathrm{WI}$ and lightness values of $\mathrm{CH}$ films and yielded films with a yellower, more saturated color (lower hue values and higher chroma). This affected both mono and bilayer films. Therefore, bilayer films were darker than CS monolayers with a more saturated yellowish, especially when incorporated essential oils.

Table 4. Lightness $\left(\mathrm{L}^{*}\right)$, chroma $\left(\mathrm{C}^{*}{ }_{\mathrm{ab}}\right)$, hue $\left(\mathrm{h}^{*}{ }_{\mathrm{ab}}\right)$, whiteness index $(\mathrm{Wl})$ and gloss at $60^{\circ}$. Mean values and standard deviation, in brackets.

\begin{tabular}{lccccc}
\hline Films & $\mathbf{L}^{*}$ & $\mathbf{C}^{*}{ }_{a b}$ & $\mathbf{h}^{*}{ }_{a b}$ & WI & Gloss \\
\hline CS & $86.4(0.7)^{\mathrm{d}}$ & $5.4(0.4)^{\mathrm{a}}$ & $81(2)^{\mathrm{c}}$ & $84.9(0.2)^{\mathrm{e}}$ & $41(2)^{\mathrm{e}}$ \\
CH & $68(1)^{\mathrm{c}}$ & $10.2(0.6)^{\mathrm{b}}$ & $106.9(0.6)^{\mathrm{f}}$ & $66.4(0.9)^{\mathrm{d}}$ & $49(2)^{\mathrm{g}}$ \\
$\mathbf{C H : O E O}$ & $63.3(0.4)^{\mathrm{a}}$ & $17.64(0.12)^{\mathrm{c}}$ & $88.2(0.2)^{\mathrm{e}}$ & $59.1(0.4)^{\mathrm{b}}$ & $54(1)^{\mathrm{h}}$ \\
$\mathbf{C H : C L E O}$ & $63.5(0.5)^{\mathrm{a}}$ & $18.6(0.3)^{\mathrm{d}}$ & $88.7(0.2)^{\mathrm{e}}$ & $59.1(0.3)^{\mathrm{b}}$ & $47(2)^{\mathrm{f}}$ \\
\hline CS:CH & $70.9(0.5)^{\mathrm{d}}$ & $25.4(0.6)^{\mathrm{f}}$ & $79.9(0.4)^{\mathrm{b}}$ & $61.4(0.5)^{\mathrm{c}}$ & $23(0 .)^{\mathrm{a}}$ \\
CS:CH:OEO & $66.06(0.8)^{\mathrm{b}}$ & $26.83(0.13)^{\mathrm{g}}$ & $77.4(0.5)^{\mathrm{a}}$ & $57(1)^{\mathrm{a}}$ & $26(1)^{\mathrm{c}}$ \\
CS:CH:CLEO & $69(2)^{\mathrm{c}}$ & $22.7(0.5)^{\mathrm{e}}$ & $83.1(0.7)^{\mathrm{d}}$ & $62(1)^{\mathrm{c}}$ & $23(2)^{\mathrm{a}}$ \\
\hline Different superscripts (a-h) within the same column indicate significant differences among formulations $\left({ }^{*} \mathrm{p}<0.05\right)$.
\end{tabular}

430 The gloss of the films is linked to the morphology of their surface and generally, the 431 smoother the surface, the glossier the film. Table 4 shows the gloss values at $60^{\circ}$ of all 
monolayer and bilayer films. Incorporation of essential oils did not notably affect the gloss of the $\mathrm{CH}$ monolayers despite their potential effect on the film surface morphology due to their dispersed nature in the films, which could increase the surface roughness (Bonilla et al., 2012).

Thermo-compression in bilayers, greatly reduced the gloss of the $\mathrm{CH}$ face, which can be attributed to the rearrangement of the chains near the surface, where temperature reaches the highest value, provoking a less oriented and more disordered chain arrangement and affecting the surface roughness.

\subsection{Antimicrobial properties}

Figure 4 shows the progress over storage time (up to 7 days) of coliform counts in noncoated and coated pork meat.

$\mathrm{CH}$ monolayers were the most effective at reducing the growth of total aerobial and coliform microorganisms during the whole storage period, and the growth inhibition coincides with that previously reported by Bonilla et. al (2014).

The incorporation of essential oils into the $\mathrm{CH}$ monolayer films caused a slight increase in the microbial counts. This indicates that $\mathrm{CH}$ was more effective than the essential oils, at their final concentration in the films, in inhibiting the bacterial growth. The reduction in the effective ratio of chitosan in the films that contain essential oils explains the decrease in the antimicrobial effectiveness caused by a dilution effect (SánchezGonzález, Chiralt, González-Martínez, \& Cháfer, 2011).

Bilayer films were slightly less effective than $\mathrm{CH}$ monolayers at controlling the bacterial growth, especially at the end of incubation time, where more marked differences between films were observed. The loss of antimicrobial capacity of $\mathrm{CH}$ in bilayers could be due to the partial deamination of the $\mathrm{CH}$ chains during the thermocompression step, as deduced from the thermal analysis. TGA of the bilayers do not exhibit the $\mathrm{CH}$ weight loss occurred in $\mathrm{CH}$ monolayers between $130-200^{\circ} \mathrm{C}$, which could indicate that this event occurred during the film processing. Several authors indicated the role of amino 

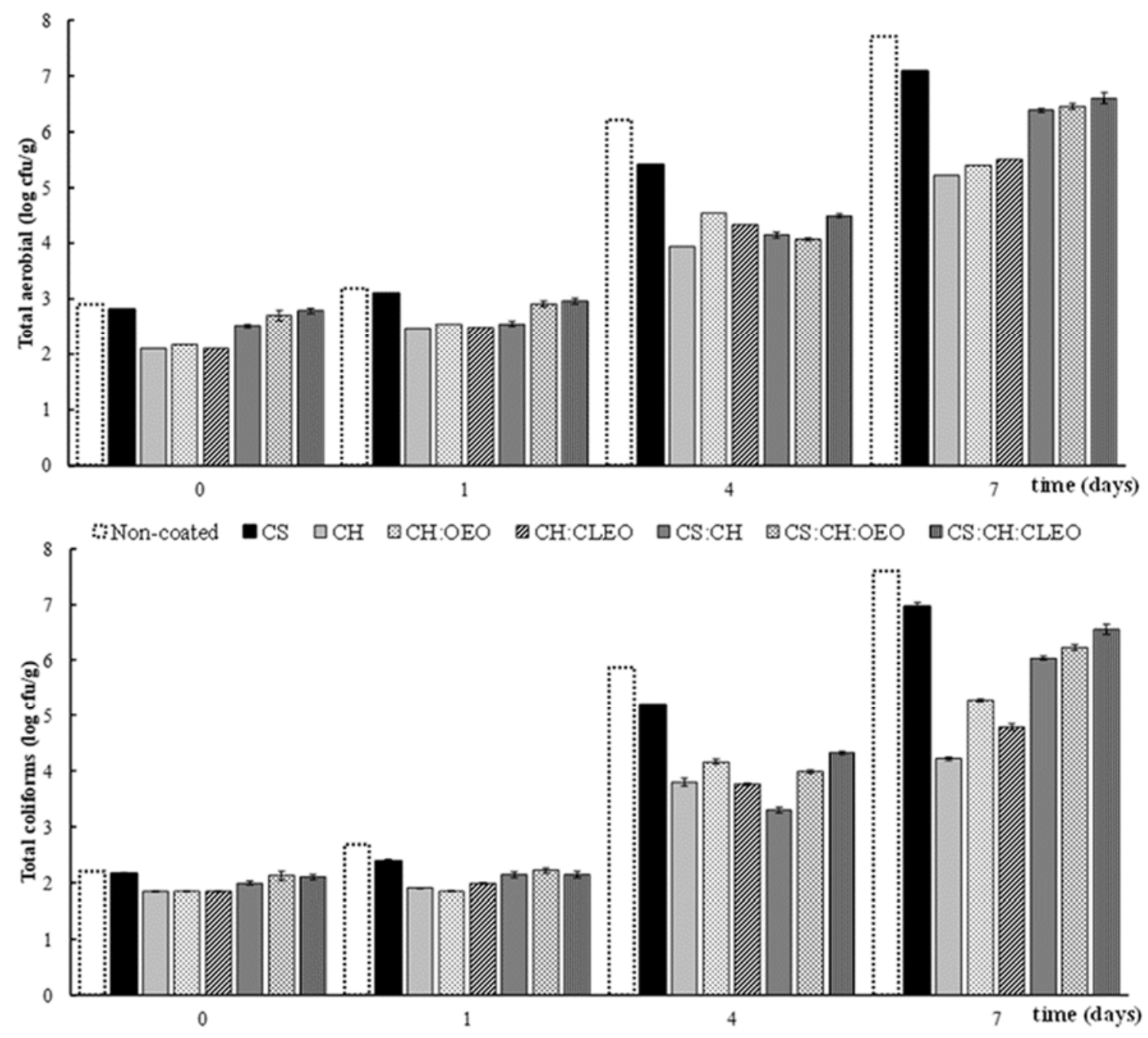

Figure 4. Total aerobial and coliform counts of non-coated minced pork samples and samples coated with the films. Mean values and standard deviation.

At the end of storage, all films led to a reduction in microbial load as compared to noncoated samples and samples coated with pure CS films, revealing the antimicrobial action of $\mathrm{CH}$, affected to a different extent by the dilution effect in the matrix and thermal treatment. 


\section{Conclusion}

473 It was possible to obtain starch-chitosan bilayer films, containing or not essential oils in the chitosan layer, by thermo-compression, exhibiting a good interfacial adhesion between the polymer layers. Starch-chitosan bilayer films showed better mechanical resistance than starch monolayers, although they were less stretchable due to the interfacial control of the film fracture. Bilayer films were slightly less transparent but showed acceptable optical properties. Chitosan was effective at controlling the bacterial growth in sliced pork meat. However, the thermal treatment used to obtain the bilayers reduced its effectiveness, revealing the loss of amino groups during treatment, as it was also confirmed by thermal analyses. Essential oils did not exhibit antimicrobial action in chitosan mono and bilayers when applied to pork meat. The final amount of essential oils in the films could be very limited by the potential losses occurred during the casting and thermoprocessing methods that were used for film production. Other strategies to incorporate the antimicrobial essential oils in the films should be used in order to improve the final retention of essential oils in polymer matrices and their effective release into the food media to exceed the minimally inhibitory concentration.

\section{Acknowledgements}

492 The authors acknowledge the financial support provided by the Spanish Ministerio de Economía y Competividad (Projects AGL2013-42989-R and AGL2016-76699-R). (PRONABEC).

\section{References}


1. ASTM (1995). Standard test methods for water vapor transmission of materials. In Standards designations: E96-95. Annual book of ASTM standards, (pp. 406 - 413). Philadelphia, PA: American Society for Testing and Materials.

2. ASTM (1999). Standard test method for specular gloss. Standard Designations: D523. In Annual book of ASTM standards. Philadelphia, PA: American Society for Testing and Materials.

3. ASTM (2001). Standard test method for tensile properties of thin plastic sheeting. In Standard D882 Annual book of American standard testing methods, (pp. 162 170). Philadelphia, PA: American Society for Testing and Materials.

4. ASTM (2002). Standard test method for oxygen gas transmission rate through plastic film and sheeting using a coulometric sensor. Standard Designations: 398595. In Annual book of ASTM standards. Philadelphia, PA: American Society for Testing and Materials.

5. Atarés, L., Bonilla, J., \& Chiralt, A., (2010). Characterization of sodium caseinatebased edible films incorporated with cinnamon or ginger essential oils. Journal of Food Engineering, 100, 678-687.

6. Avérous, L., Moro, L., Dole, P., \& Fringan, C. (2000). Properties of thermoplastic blends: starch-polycaprolactone. Polymer, 41, 4157 - 4167.

7. Avérous, L., Fringant, C., \& Moro, L.(2001). Starch-Based Biodegradable Materials Suitable for Thermoforming Packaging. Starch/Stärke, 53, 368 - 371.

8. Ayala-Zavala, J., Soto-Valdez, H., González-León, A., Álvarez-Parrilla, E., MartínBelloso, O., \& González-Aguilar, G. (2008). Microencapsulation of cinnamon leaf (Cinnamomum zeylanicum) and garlic (Allium sativum) oils in -cyclodextrin. Journal of Inclusion Phenomena and Macrocyclic Chemistry, 60, 359 - 368.

9. Bakkali, F., Averbeck, S., Averbeck, D., \& Idaomar, I. (2008). Biological effects of essential oil sea review. Food and Chemical Toxicology, 46,446 - 475. 
10. Bonilla, J., Talón, E., Atarés, L., Vargas, M., \& Chiralt, A. (2013). Effect of the incorporation of antioxidants on physicochemical of wheat starch-chitosan films. Journal of Food Engineering, 118 (3), 271 - 278.

11. Bonilla, J., Atarés, L., Vargas, M., \& Chiralt, A. (2014). Physical, structural and antimicrobial properties of poly vinyl alcohol - chitosan biodegradable films. Food Hydrocolloids, 35, $463-470$.

12. Bonilla, J., Vargas, M., Atarés, A., \& Chiralt, A. (2014). Effect of Chitosan Essential Oil Films on the Storage-Keeping Quality of Pork Meat Products. Food and Bioprocess Technology, 7, 2443 - 2450.

13. Burt, S. (2004). Essential oils: their antibacterial properties and potential applications in foods-a review. International Journal of Food Microbiology, 94, 223 $-253$.

14. Chang, S., Chen, P., \& Chang, S. (2001). Antibacterial activity of leaf essential oils and their constituents from Cinnamomum osmophloeum. Journal of Ethnopharmacology, 77, $123-127$.

15. Chen, C. H., Wang, F. Y., Mao, C. F., Liao, W. T., \& Hsieh, C. D. (2008). Studies of chitosan: II. Preparation and characterization of chitosan/poly (vinyl alcohol)/ gelatin ternary blend films. International Journal of Biological Macromolecules, 43, 37 - 42.

16. De Sousa J. P., de Azerêdo G. A., de Araújo Torres R., da Silva Vasconcelos M. A., da Conceição M. L., \& de Souza E. L. (2012). Synergies of carvacrol and 1,8cineole to inhibit bacteria associated with minimally processed vegetables. International Journal of Food Microbiology 154, 145 - 151.

17. De Brito, D., \& Campana-Filho, S.P. (2007). Kinetics of the thermal degradation of chitosan. Thermochimica Acta, 465, 73 - 82.

18. Doane, W., Swanson, C., \& Fanta,G. (1992). Emerging polymeric materials based on starch- ACS Symposium Series, 476, 197 - 230.

19. Dutta, P.K., Dutta, J., \& Tripathi, V.S. (2004).Chitin and chitosan : Chemistry, properties and applications. Journal of Scientific \& Industrial Research, 63, 20 - 31. 
20. Flores, S., Costa, D., Yamashita, F., Gerschenson, L., \& Grossmann Eiras, M. (2010). Mixture design for evaluation of potassium sorbate and xanthan gum effect on properties of tapioca starch films obtained by extrusion. Materials Science \& Technology, 30(1), 196 - 202.

21. Ghanbarzadeh, B., \& Oromiehi, A. R. (2009). Thermal and mechanical behavior of laminated protein films. Journal of Food Engineering, 90,517 - 524.

22. Hutchings, J. B. (1999). Food color and appearance (2nd Ed.). Gaithersburg, Maryland, USA: Aspen Publishers, Inc.

23. Jiménez, A., Fabra, M. J., Talens, P., \& Chiralt, A. (2012). Effect of re-crystallization on tensile, optical and water vapour barrier properties of corn starch films containing fatty acids. Food Hydrocolloids, 26, $302-310$.

24. Khan, B., Bilal Khan Niazi, M., Samin, G., \& Jahan, Z. (2017). Thermoplastic Starch: A Possible Biodegradable Food Packaging Material—A Review. Journal of Food Process Engineering, 40, e12447.

25. Kim, H., Park, S., \& Park, H. (2004). Inactivation of Escherichia coli O157:H7 by cinnamic aldehyde purified from Cinnamomum cassias hoot. Food Microbiology, $21,105-110$.

26. Kong, M., Chen, X.G., Xing, K., \& Park, H.J. (2010). Antimicrobial properties of chitosan and mode of action: A state of the art review. International Journal of Food Microbiology, 144, $51-63$.

27. Lertsutthiwong, P., Ng, C., Chandrkrachang, S., \& Stevens,W. (2002). Effect of chemical treatment on the characteristics of shrimp chitosan, Journal of Metals, Materials and Minerals, 12, $11-18$.

28. Lewandowska, K. (2009). Miscibility and thermal stability of poly(vinyl alcohol)/ chitosan

29. mixtures. Thermochimica Acta, 493, 42 - 48. 
30. López, O., Garcia, A., Villar, M., Gentili, A., Rodriguez, M., Albertengo, L. (2014). Thermo-compression of biodegradable thermoplastic corn starch films containing chitin and chitosan. Food Science and Technology, 57, 106106 - 1515.

31. Lv F., Liang H., Yuan Q., \& Li C. (2011). In vitro antimicrobial effects and mechanism of action of selected plant essential oil combinations against four foodrelated microorganisms. Food Research International, 44, 3057 - 3064.

32. Mali, S., Grossmann, M. V., García, M., Martino, M., \& Zaritzky, N. (2006). Effects of controlled storage on thermal, mechanical and barrier properties of plasticized films from different starch sources. Journal of Food Engineering, 75, 453 - 460.

33. Mc Hugh, T. H., Avena-Bustillos, R., \& Krochta, J. M. (1993). Hydrophobic edible films: modified procedure for water vapour permeability and explanation of thickness effects. Journal of Food Science, 58, 899 - 903.

34. Naushad Emmambux, N., \& Stading, M. (2007). In situ tensile deformation of zein films with plasticizers and filler materials. Food Hydrocolloids, 21, 1245 - 1255.

35. Ortega-Toro, R., Jiménez, A., Talens, P \& Chiralt, A. (2014). Properties of starchhydroxypropyl methylcellulose based films obtained by compression molding. Carbohydrate Polymers, 109, 155 - 165.

36. Park, I., Lee, H., Lee, S., Park, J., \& Ahn, Y. (2000). Insecticidal and fumigant activities of Cinnamomum cassia bark-derived materials against Mechoris ursulus (Coleoptera: Attelabidae). Journal of Agriculture and Food Chemistry, 48, 2528 2531.

37. Pelissari, F. M., Yamashita, F., García, M. A., Martino, M. N., Zaritzky, N. E., \& Grossmann, M. V. E. (2012). Constrained mixture design applied to the development of cassava starch-chitosan blown films. Journal of Food Engineering, $108,262-267$.

38. Perdones, A., Vargas, M., Atarés, L. \& Chiralt, A. (2014). Physical, antioxidant and antimicrobial properties of chitosan - cinnamon leaf oil films as affected by oleic acid. Food Hydrocolloids, 36, $256-264$. 
39. Ramos, M., Jiménez, A., Peltzer, M., \& Garrigós, M. C. (2012). Characterization and

40. antimicrobial activity studies of polypropylene films with carvacrol and thymol for active packaging. Journal of Food Engineering, 109, 513 - 519.

41. Reyes-Chaparro, P., Gutierrez-Mendez,N., Salas-Muñoz,E., Ayala-Soto,J.G., Chavez-Flores, D., \& Hernández-Ochoa, L. (2015). Effect of the Addition of Essential Oils and Functional Extracts of Clove on Physicochemical Properties of Chitosan-Based Films. International Journal of Polymer Science, 714, 254 - 260.

42. Sánchez-González, L., Chiralt, A., González-Martínez, C., \& Cháfer, M. (2011). Effect of essential oils on properties of film forming emulsion and films based on hydroxypropylmethylcellulose and chitosan. Journal of Food Engineering, 105, 246

43. Shogren, R. (1998). Starch: Properties and Materials Applications. In Biopolymers from renewable resources (Ed. D. L.Kaplan), Springer-Verlag, Berlin, pp. 30-46.

44. Swanson, C. L., Shogren, R. L., Fanta, G. F., \& Imam, S. H. J. (1993). Starchplastic materials-Preparation, physical properties, and biodegradability (a review of recent USDA research). Journal of Environmental Polymer Degradation, 1,155 166.

45. Singh, G., Maurya, S., de Lampasona, M. P., \& Catalan, C. A. N. (2007). A comparison of chemical, antioxidant and antimicrobial studies of cinnamon leaf and bark volatile oils, oleoresins and their constituents. Food and Chemical Toxicology, $45,1650-1661$

46. Singh, H., Srivastava, M., Singh, A., \& Srivastava, A. (1995). Cinnamon bark oil, a potent fungitoxicant against fungi causing respiratory tract mycoses. Allergy, 50, $995-999$.

47. Tomka, I. (1991). Thermoplastic starch. Advances in Experimental Medicine and Biology, 302, $627-637$. 
48. Thunwall, M., Boldizar, A., \& Rigdahl, M. (2006). Compression molding and tensile properties of thermoplastic potato starch materials. Biomacromolecules, 7, 981 986.

49. Van Soest, J.J.G. (1996). Starch plastics structure-property relationships. P\&L Press, Wageningen, Germany/ Utrecht University (Netherland).

50. Vangalapati, M., Satya, S. N., Prakash, D. V. S., \& Avanigadda, S. (2012). A review on pharmacological activities and clinical effects of cinnamon species. Research Journal of Pharmaceutical, Biological and Chemical Sciences, 3, 653-663.

51. Vargas, M., Albors, A., Chiralt, A., \& González-Martínez, C. (2009). Characterization of chitosan-oleic acid composite films. Food Hydrocolloids, 23, 536-547.

52. Vargas, M., Perdones, A., Chiralt, Cháfer, M., \& González-Martínez, C. (2011). Effect of homogenization conditions on physicochemical properties of chitosanbased film-forming dispersions and films. Food Hydrocolloids, 25, 1158-1165.

53. Verlee, A., Mincke, S., \& Stevens, C.V. (2017). Recent developments in antibacterial and antifungal chitosan and its derivatives. Carbohydrate Polymers, $164,268-283$.

54. Weska, R., Moura, J., Batista, L., Rizzi, J., \& Pinto, L. (2007). Optimization of deacetylation in the production of chitosan from shrimp wastes: use of response surface methodology, Journal of Food Engineering, 80, 749 - 753.

55. Xu, Y. X., Kimb, K. M., Hanna, M. A., \& Nag, D. (2005). Chitosan- starch composite film: preparation and characterization. Industrial Crops and Products, 21,185 - 192.

56. Youn, D., No, H., \& Prinyawiwatkul, W. (2007). Physical characteristics of decolorized chitosan as affected by sun drying during chitosan preparation, Carbohydrate Polymers, 69, $707-712$.

57. Zobel, H.F. (1988). Starch crystal transformations and their industrial importance. Starch/Stärke, 40, 1-7. 
